Supporting information for

\title{
Psathyrins: Antibacterial Diterpenoids from Psathyrella
} candolleana

Ya-Pei Liu, ${ }^{\dagger}$ Quan Dai,${ }^{\dagger}$ Wen-Xuan Wang, ${ }^{\dagger}$ Juan He,${ }^{\dagger}$ Zheng-Hui Li, ${ }^{\dagger}$ Tao Feng, ${ }^{*}{ }^{* \dagger+}$ and Ji-Kai Liu ${ }^{* \dagger}$

${ }^{\dagger}$ School of Pharmaceutical Sciences, South-Central University for Nationalities, Wuhan 430074, China

Institute for Organic Chemistry and Centre for Biomolecular Drug Research, Leibniz University Hannover, Hannover 30167, Germany

*Correspondence author: tfeng@ mail.scuec.edu.cn (T. Feng); liujikai@mail.scuec.edu.cn (J.-K. Liu)

\section{List of Supporting Information}

1. Structural elucidation of psathyrin A (1)

2. ${ }^{13} \mathrm{C}$ NMR and ECD calculations for psathyrin B (2)

3. NMR spectra and MS for psathyrins A (1) and B (2)

3.1. NMR spectra and HR-ESIMS for psathyrin A (1)

3.2. NMR spectra and HR-ESIMS for psathyrin B (2) 


\section{Structural elucidation of psathyrin A (1)}

From the analysis of the ${ }^{1} \mathrm{H}-{ }^{1} \mathrm{H}$ COSY data, several fragments were established (Figure S1). Based on these fragments, detailed analysis of the HMBC data established the planar structure, in particular with the $\mathrm{HMBC}$ correlations related to two methyl singlets at $\delta_{\mathrm{H}} 1.01\left(3 \mathrm{H}, \mathrm{s}, \mathrm{H}_{3}-17\right)$ and $1.13\left(3 \mathrm{H}, \mathrm{s}, \mathrm{H}_{3-}\right.$ 16). As shown in Figure 2, $\mathrm{H}_{3}-17$ showed four key HMBC correlations to $\delta_{\mathrm{C}} 56.4$ (s, C-11), 74.4 (s, C-1), 39.0 (t, C-10), and 46.6 (d, C-12), establishing the connectivity of C-11 with C-1, C-10, C-12, and $\mathrm{C}-17$, respectively. The $\mathrm{HMBC}$ correlations from $\delta_{\mathrm{H}} 2.27$ and $1.98\left(\mathrm{H}_{2}-13\right)$ to $\delta_{\mathrm{C}} 219.7(\mathrm{~s}, \mathrm{C}-14)$ and $\mathrm{C}-1$ revealed linkage of $\mathrm{C}-13 / \mathrm{C}-14 / \mathrm{C}-1$, establishing ring A as a cyclopentane with an isopropyl substituent. HMBC correlations from $\mathrm{H}_{3}-16$ to $\delta_{\mathrm{C}} 54.8$ (s, C-8), 47.4 (d, C-7), 42.2 (t, C-9), and C-1 constructed the connectivity of C-8 with C-1, C-7, C-9, and C-16, establishing the five membered ring B structure. The HMBC correlation from $\delta_{\mathrm{H}} 2.91(1 \mathrm{H}, \mathrm{d}, J=10.2 \mathrm{~Hz}, \mathrm{H}-2)$ to $\mathrm{C}-1$, as well as the fragments achieved by the ${ }^{1} \mathrm{H}-{ }^{1} \mathrm{H}$ COSY data, indicated that an unusual four-membered ring $\mathrm{C}$ from C-1, C-2, C-7, and C-8 (Figure S1) was present. In the HMBC spectrum, signals at $\delta_{\mathrm{H}} 2.24$ and 1.83 for $\mathrm{H}-5$ showed $\mathrm{HMBC}$ correlations to $\delta_{\mathrm{C}} 137.2$ (s, C-4) and 122.7 (d, C-3). These data, along with the ${ }^{1} \mathrm{H}-{ }^{1} \mathrm{H} \operatorname{COSY}$ data as given above, supported the six-membered ring D. A hydroxy methylene group placed at C-4 of the double bond was indicated by the HMBC correlations from $\delta_{\mathrm{H}} 3.95(1 \mathrm{H}, \mathrm{d}, J=$ 12.6 Hz, H-15a) and $3.91(1 \mathrm{H}, \mathrm{d}, J=12.6 \mathrm{~Hz}, \mathrm{H}-15 \mathrm{~b})$ to $\mathrm{C}-4, \mathrm{C}-3$, and C-5. By detailed analysis of ${ }^{1} \mathrm{H}-{ }^{1} \mathrm{H}$ COSY and $\mathrm{HMBC}$ data, the planar structure of compound $\mathbf{1}$ was elucidated as a 5/5/4/6-fused tetracyclic system, which represents a new natural diterpene carbon skeleton. 
A ROESY experiment was performed to elucidate the relative configuration as shown in Figure S1.

The result of a single crystal X-ray diffraction for $\mathbf{1}$ not only confirmed the structure as elucidated above but also determined the absolute configuration (Flack parameter $=0.02(9)$, CCDC: 1944252).

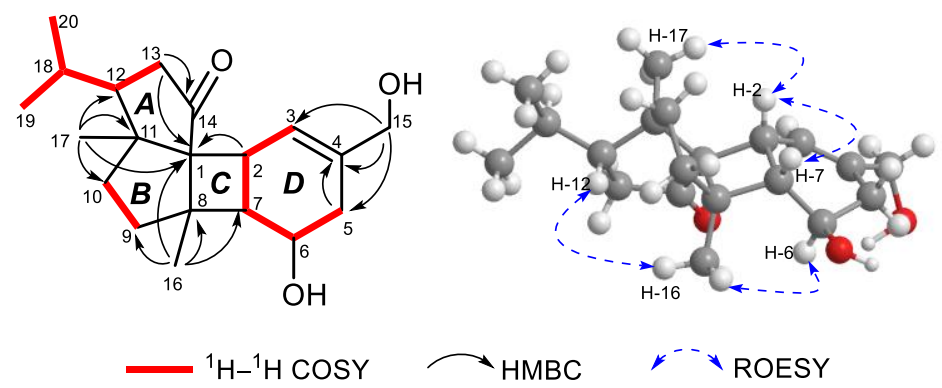

Figure S1. Key 2D NMR correlations of $\mathbf{1 .}$ 


\section{2. ${ }^{13} \mathrm{C}$ NMR and ECD calculations for psathyrin $B(2)$}

Conformers of 2 were generated by Spartan 16. ${ }^{1}$ The conformational search used Molecular Mechanics with MMFF94S. All these conformers were further optimized by the density functional theory method at the B3LYP/6-311G(d,p) level by Gaussian 09 program package. ${ }^{2}$ GIAO ${ }^{13} \mathrm{C}$ NMR was calculated on mPW1PW91/6-31G* (IEFPCM) level of theory. The calculated shielding tensors were Boltzmann averaged according to their Gibbs free energy. The shielding tensors were linearly regressed with experimental chemical shifts to yield linear formulas, based on which the calculated chemical shifts were converted from shielding tensors. The ECD were calculated using mPW1PW91/6-311G+(d,p) level in methanol with PCM model. The calculated ECD curves and weighted ECD were all generated using SpecDis 1.60 with $\sigma=0.2 \mathrm{eV}$, and UV shift $-8 \mathrm{~nm}$, respectively. ${ }^{3,4}$
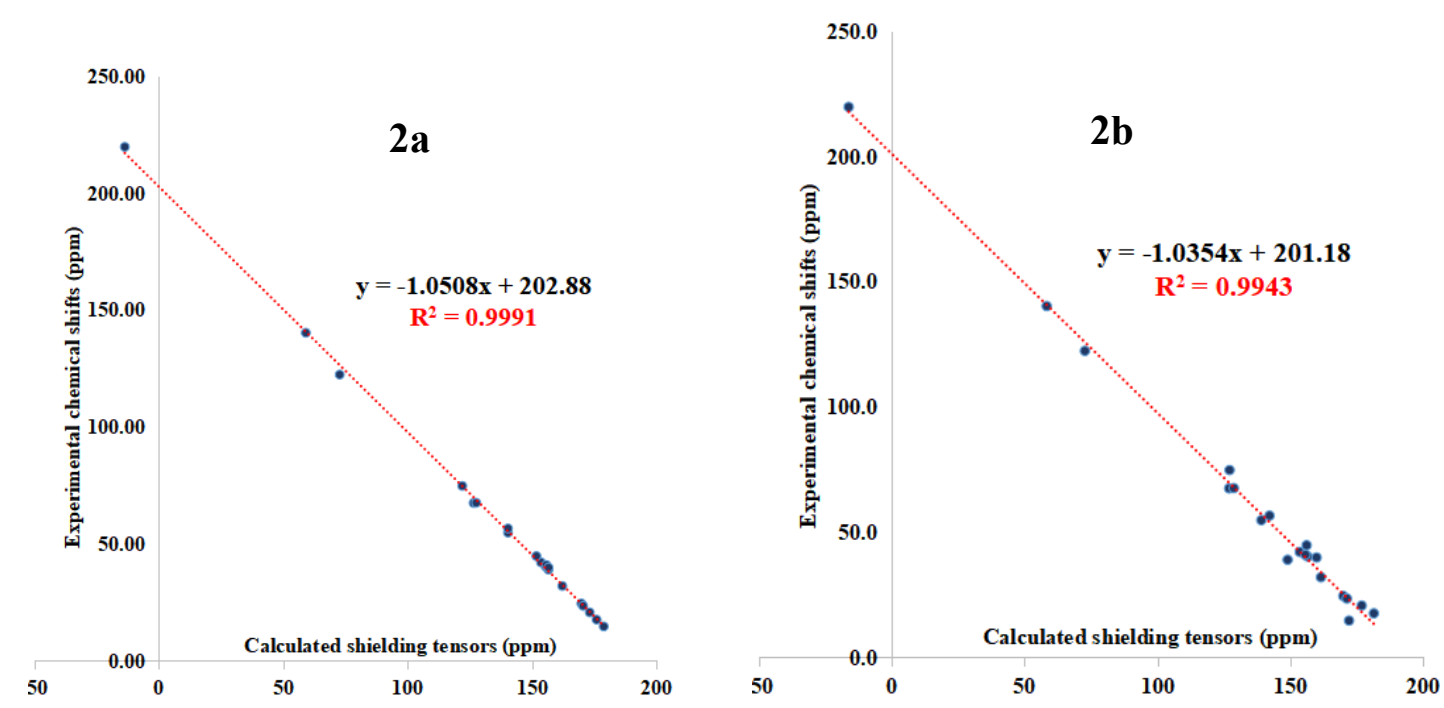

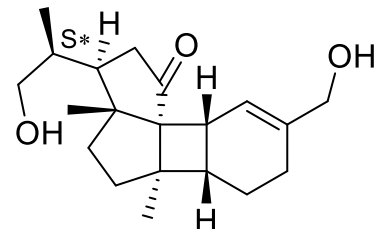

$2 a$

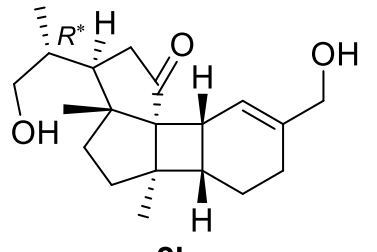

2b

Figure S2. Linear regressions between calculated shielding tensors of $\mathbf{2 a}$ and $\mathbf{2} \mathbf{b}$ with experimental chemical shifts of 2 . 


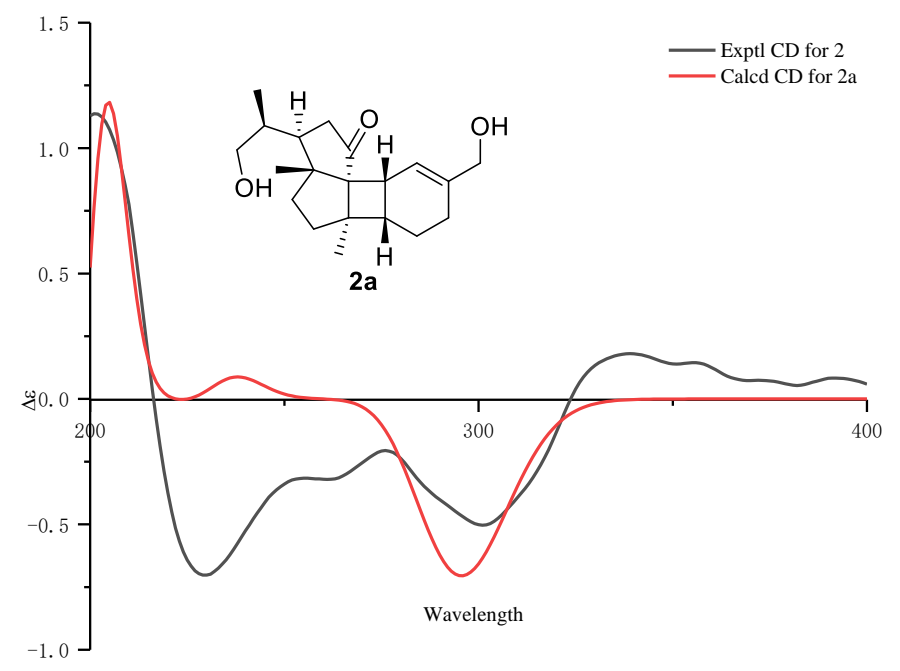

Figure S3. Comparison of the calculated ECD spectra for $\mathbf{2 a}$ with the experimental spectrum of $\mathbf{2}$ in methanol with PCM model.

Table S1. Energy analysis for conformers of $2 \boldsymbol{a A}-\mathbf{2} \boldsymbol{a} \boldsymbol{U}$ at B3LYP/6-311G+(d) level in the gas phase

\begin{tabular}{cccccccc}
\hline Species & $E^{\prime}=E+Z P E$ & $E$ & $H$ & $G$ & $\Delta G$ & $\Delta E(\mathrm{kcal} / \mathrm{mol})$ & $P E \%$ \\
\hline $\mathbf{2 a A}$ & -1005.61142 & -1005.588243 & -1005.587299 & -1005.662395 & 0.003532 & 2.2163636 & $1.74 \%$ \\
$\mathbf{2 a B}$ & -1005.614286 & -1005.591783 & -1005.590839 & -1005.663903 & 0.002024 & 1.2700792 & $8.60 \%$ \\
$\mathbf{2 a C}$ & -1005.614224 & -1005.591733 & -1005.590789 & -1005.663922 & 0.002005 & 1.2581565 & $8.77 \%$ \\
$\mathbf{2 a D}$ & -1005.612574 & -1005.589934 & -1005.58899 & -1005.66274 & 0.003187 & 1.9998728 & $2.51 \%$ \\
$\mathbf{2 a E}$ & -1005.613495 & -1005.59089 & -1005.589946 & -1005.663381 & 0.002546 & 1.5976392 & $4.94 \%$ \\
$\mathbf{2 a F}$ & -1005.615158 & -1005.59222 & -1005.591276 & -1005.665927 & 0 & 0.0000000 & $73.44 \%$ \\
\hline
\end{tabular}

$E, E^{\prime}, H, G$ : total energy, total energy with zero point energy $(Z P E)$, enthalpy, and Gibbs free energy

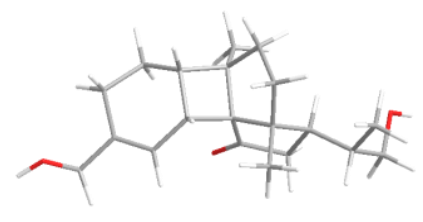

$2 \mathrm{aA}$

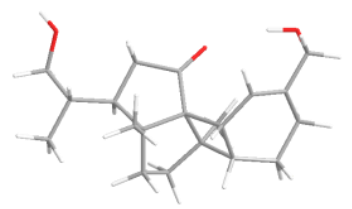

$2 \mathrm{aD}$

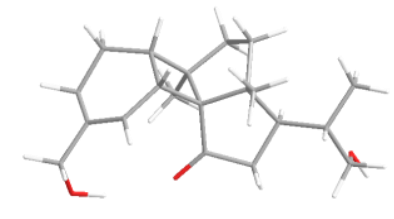

$2 \mathrm{aB}$

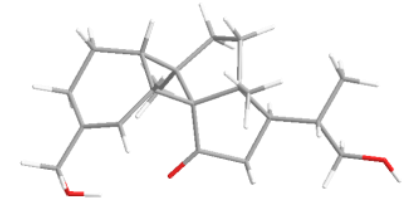

$2 \mathrm{aE}$

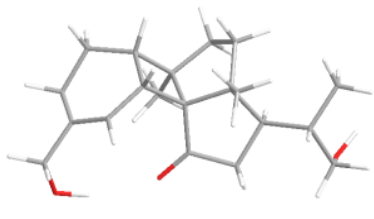

$2 \mathrm{aC}$

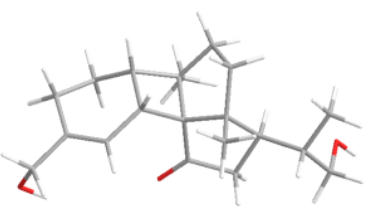

$2 \mathrm{aF}$

Figure S4. Main conformers of $\mathbf{2 a}$.

References 
(1) Halgren, T. A.; MMFF VII. Characterization of MMFF94, MMFF94s, and other widely available force fields for conformational energies and for intermolecular-interaction energies and geometries, J. Comput. Chem. 1999, 20, 730748.

(2) Gaussian 09, Revision A.02, Frisch, M. J.; Trucks, G. W.; Schlegel, H. B.; Scuseria, G. E.; Robb, M. A.; Cheeseman, J. R.; Scalmani, G.; Barone, V.; Petersson, G. A.; Nakatsuji, H.; Li, X.; Caricato, M.; Marenich, A.; Bloino, J.; Janesko, B. G.; Gomperts, R.; Mennucci, B.; Hratchian, H. P.; Ortiz, J. V.; Izmaylov, A. F.; Sonnenberg, J. L.; Williams-Young, D.; Ding, F.; Lipparini, F.; Egidi, F.; Goings, J.; Peng, B.; Petrone, A.; Henderson, T.; Ranasinghe, D.; Zakrzewski, V. G.; Gao, J.; Rega, N.; Zheng, G.; Liang, W.; Hada, M.; Ehara, M.; Toyota, K.; Fukuda, R.; Hasegawa, J.; Ishida, M.; Nakajima, T.; Honda, Y.; Kitao, O.; Nakai, H.; Vreven, T.; Throssell, K.; Montgomery, J. A.; Peralta, Jr., J. E.; Ogliaro, F.; Bearpark, M.; Heyd, J. J.; Brothers, E.; Kudin, K. N.; Staroverov, V. N.; Keith, T.; Kobayashi, R.; Normand, J.; Raghavachari, K.; Rendell, A.; Burant, J. C.; Iyengar, S. S.; Tomasi, J.; Cossi, M.; Millam, J. M.; Klene, M.; Adamo, C.; Cammi, R.; Ochterski, J. W.; Martin, R. L.; Morokuma, K.; Farkas, O.; Foresman, J. B.; Fox, D. J.; Gaussian, Inc., Wallingford CT, 2016.

(3) Zhao, Z. Z.; Chen, H. P.; Wu, B.; Zhang, L.; Li, Z. H.; Feng, T.; Liu, J. K. J. Org. Chem, 2017, 82, 7974-7979.

(4) Bruhn, T.; Schaumlöffel, A.; Hemberger, Y.; Bringmann, G. S. University of Wuerzburg: Germany. Version 1.60, 2012. 
3. NMR spectra and MS for psathyrins $A$ (1) and $B$ (2)

3.1. NMR spectra and HR-ESIMS for psathyrin $A$ (1)

${ }^{1} \mathrm{H}$ NMR for psathyrin A (1)

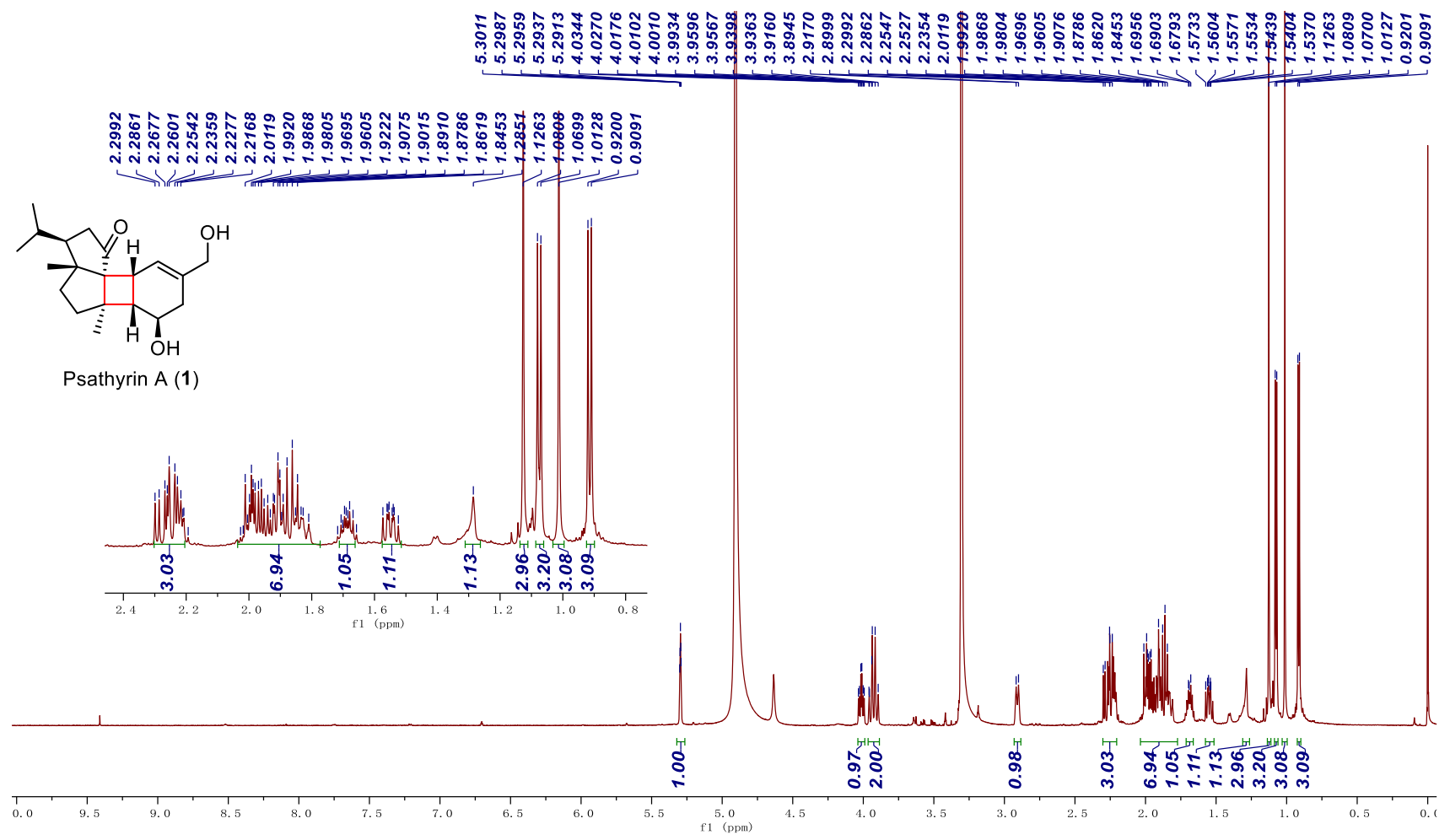

${ }^{13} \mathrm{C}$ NMR and DEPT for psathyrin A (1)
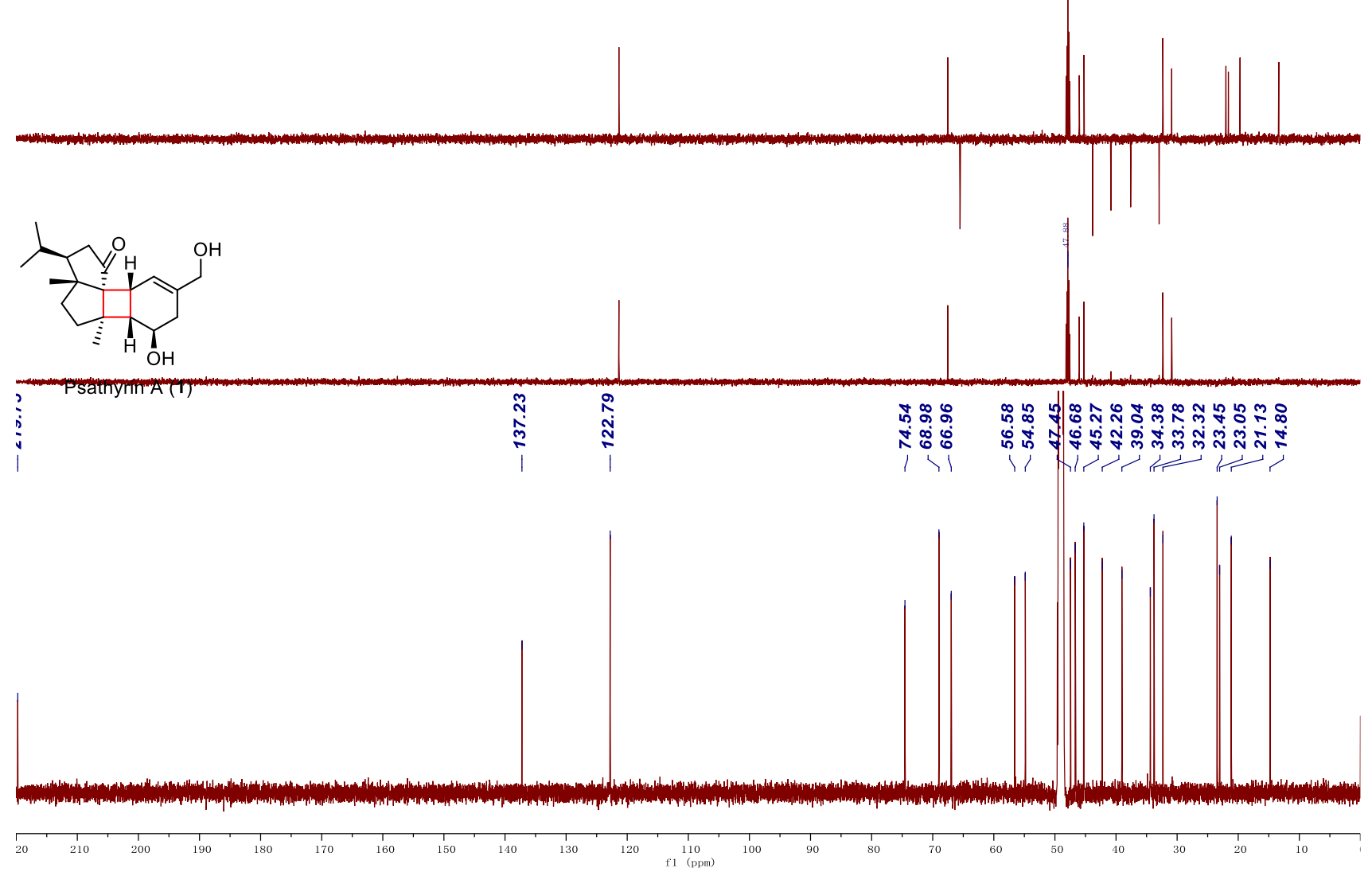
HSQC for psathyrin A (1)
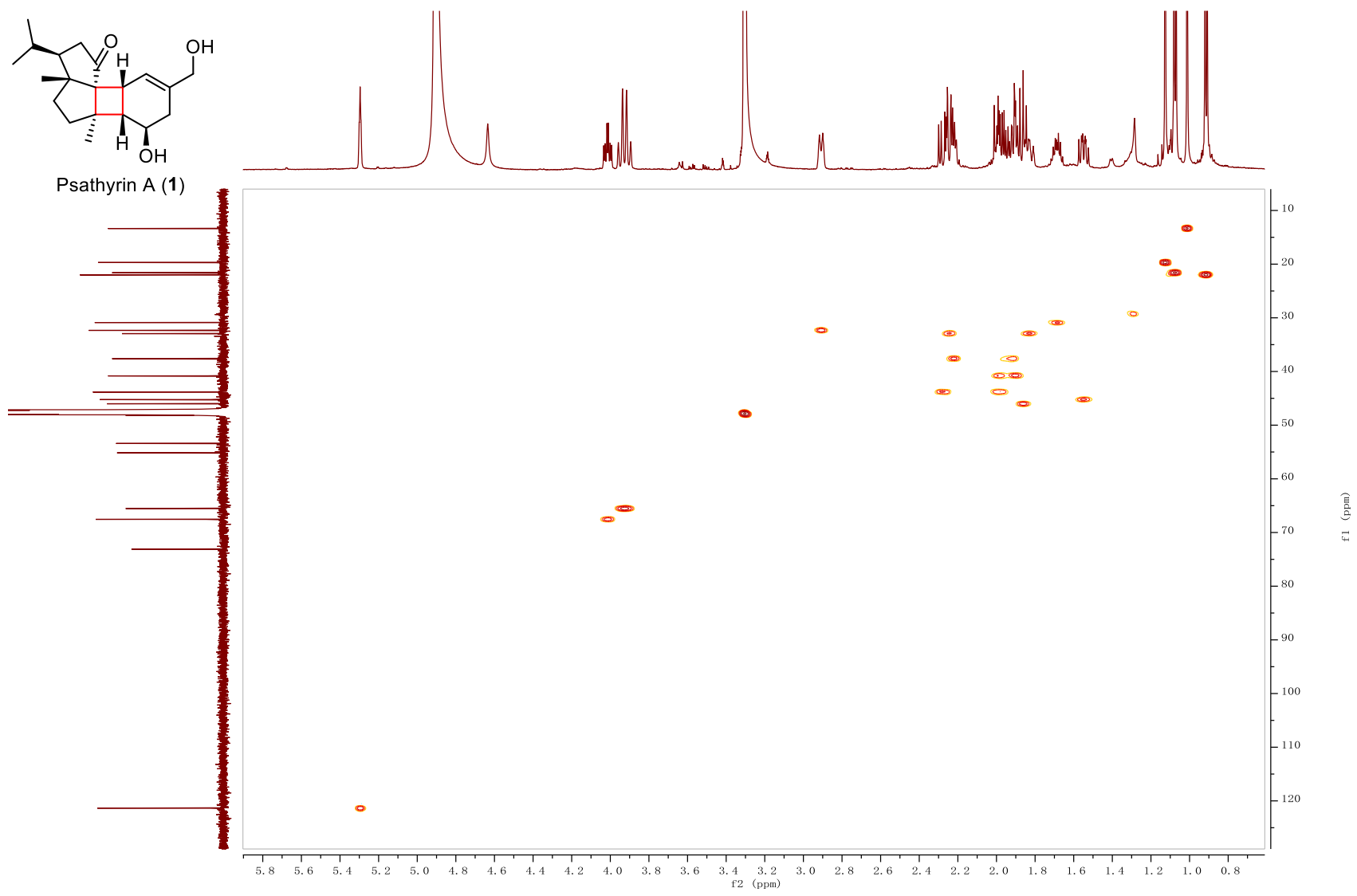

HMBC for psathyrin A (1)
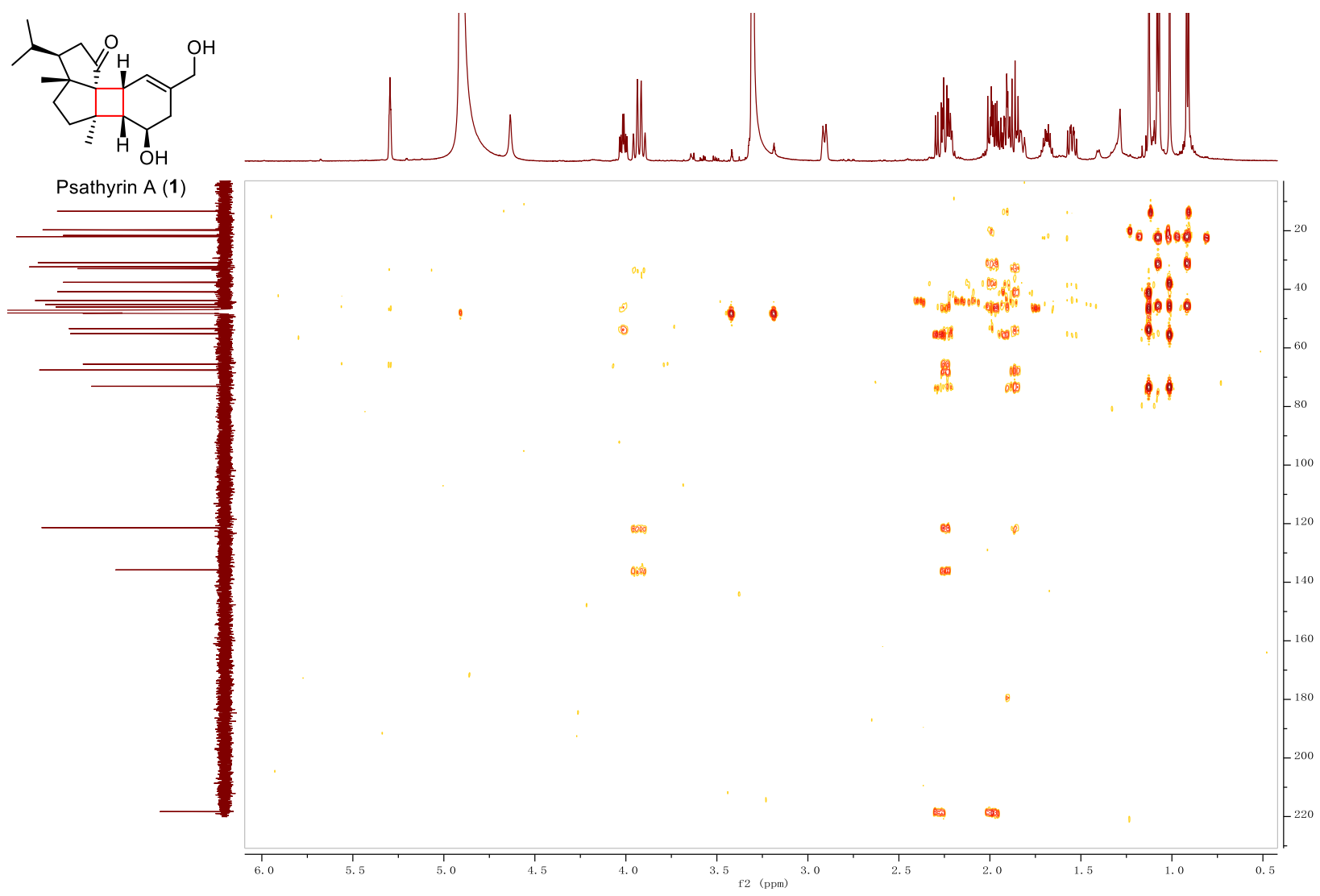
${ }^{1} \mathrm{H}-{ }^{1} \mathrm{H}$ COSY for psathyrin A (1)

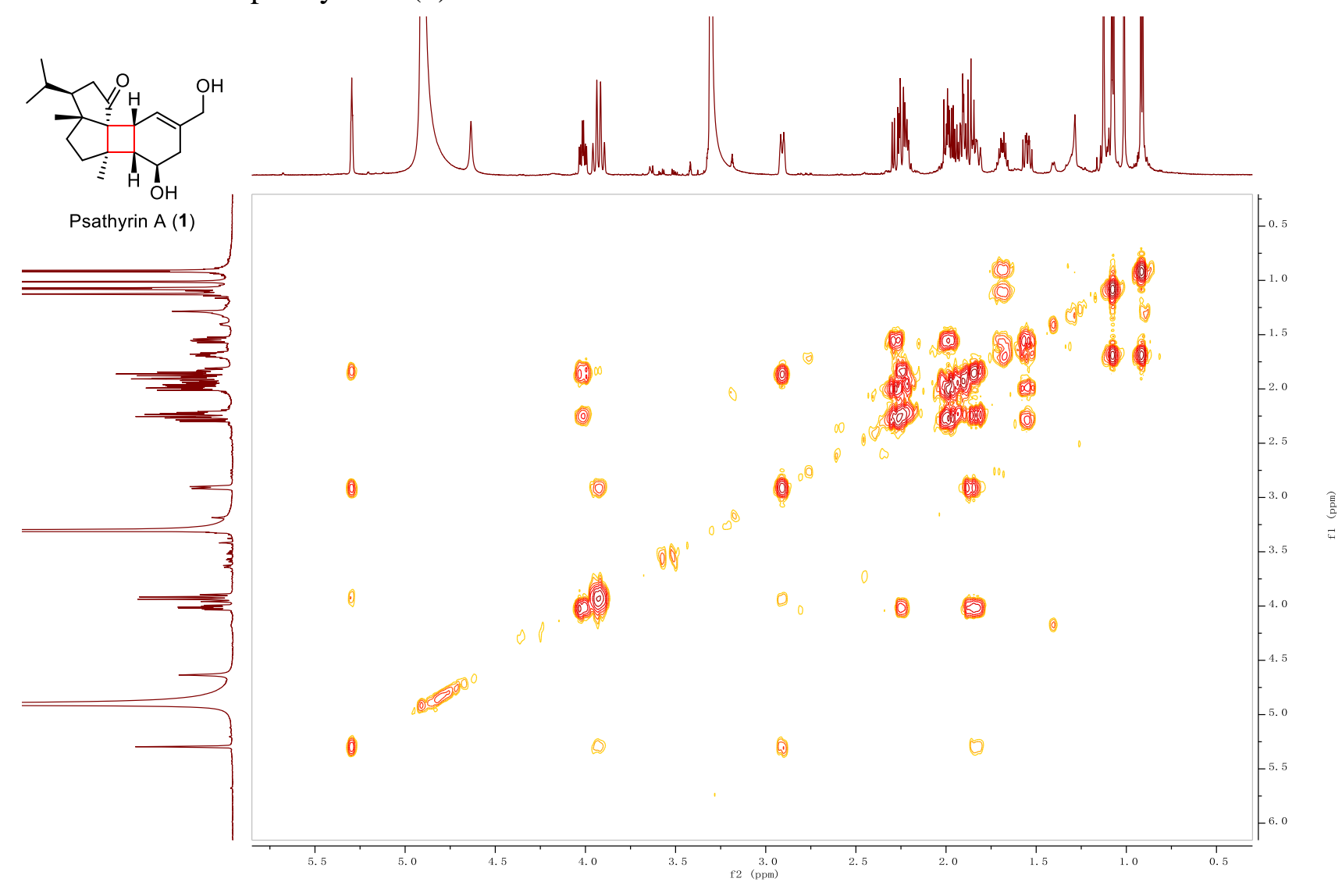

ROESY for psathyrin A (1)

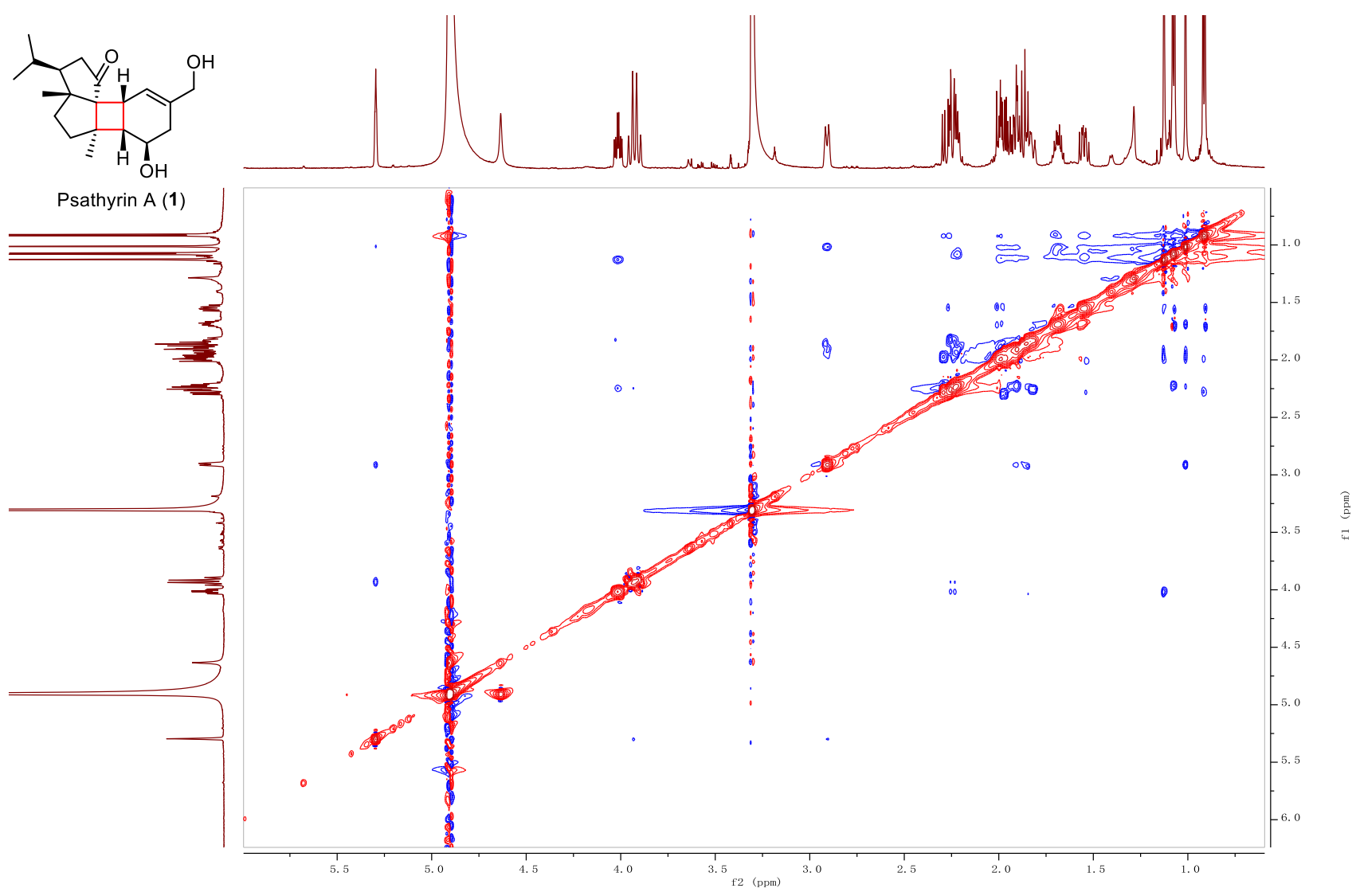


HR-ESIMS for psathyrin A (1)

LLb-43 \#11 RT: 0.15 AV: 1 NL: $1.43 E 8$

T: FTMS + p ESI Full ms [100.0000-1100.0000]

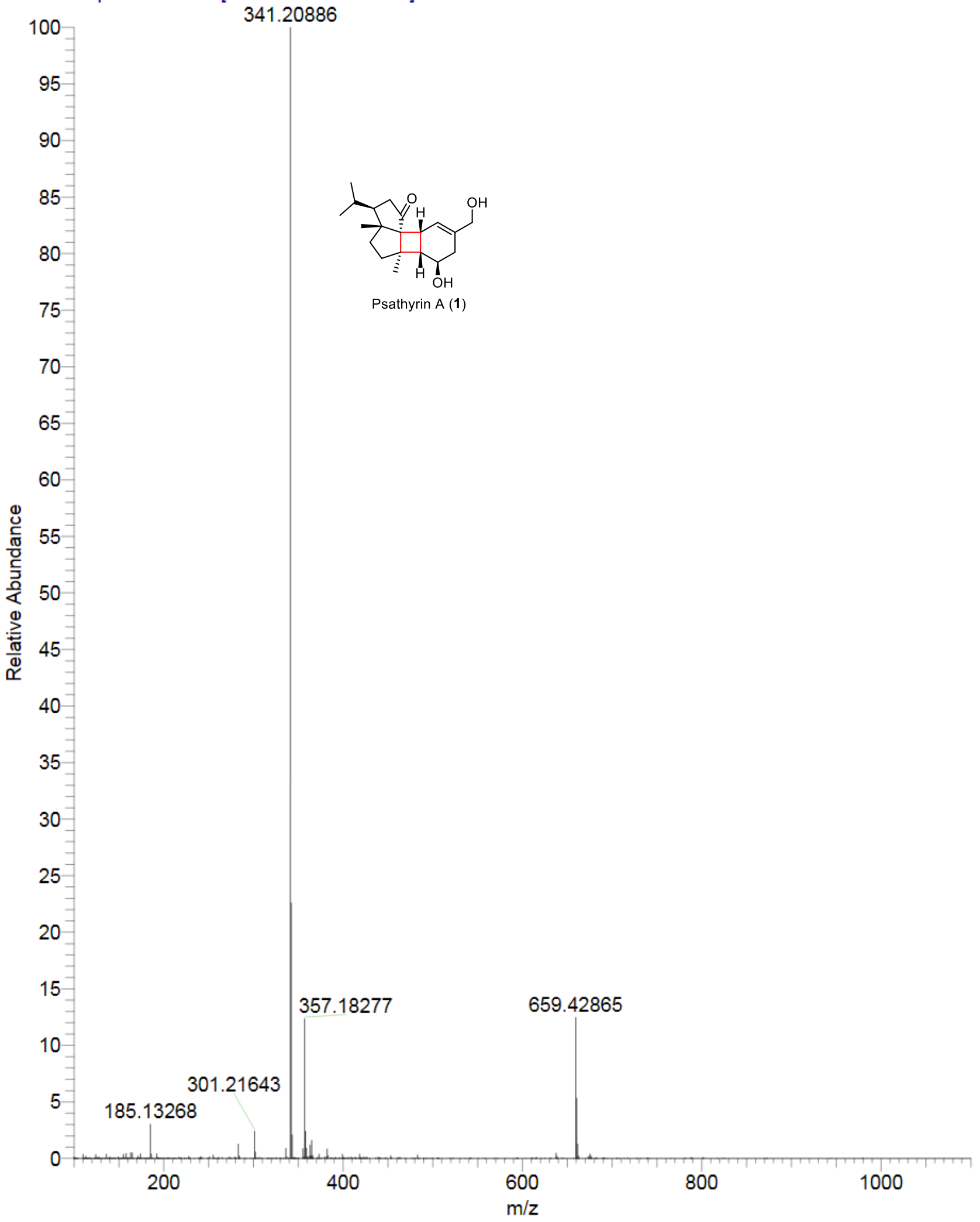


3.1. NMR spectra and HR-ESIMS for psathyrin B (2)

${ }^{1} \mathrm{H}$ NMR for psathyrin B (2)

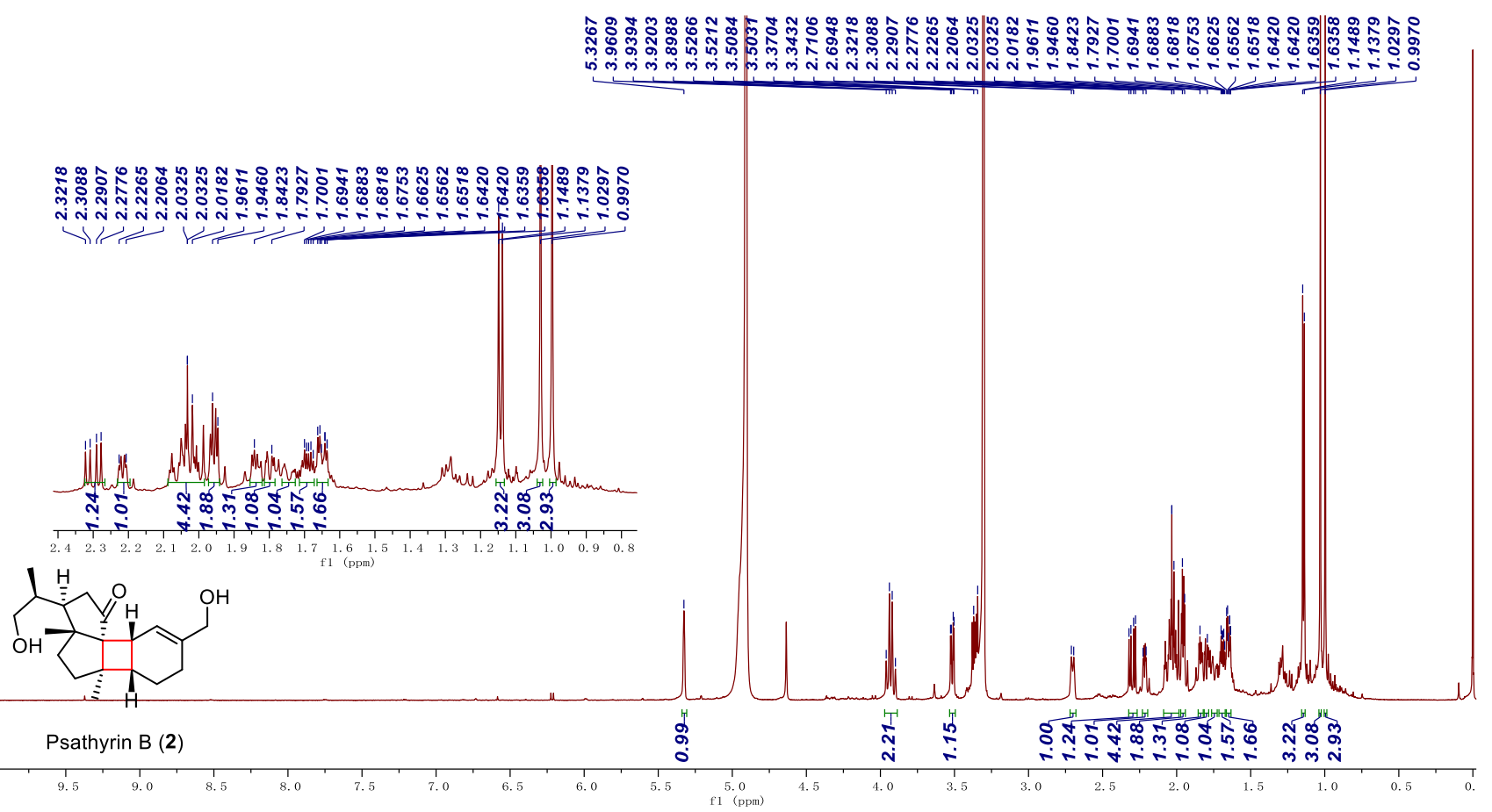

${ }^{13} \mathrm{C}$ NMR and DEPT for psathyrin B (2)
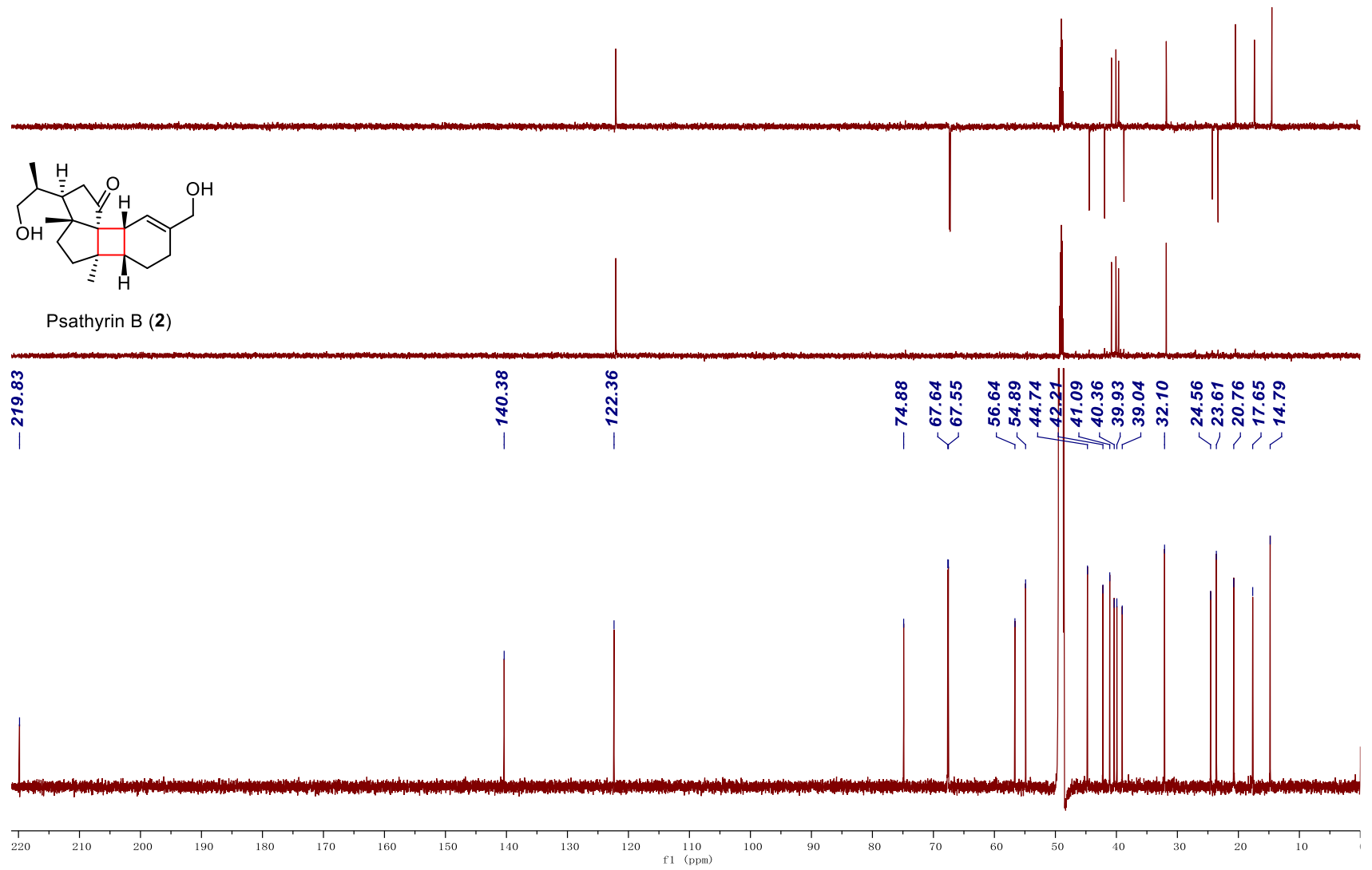
HSQC for psathyrin B (2)
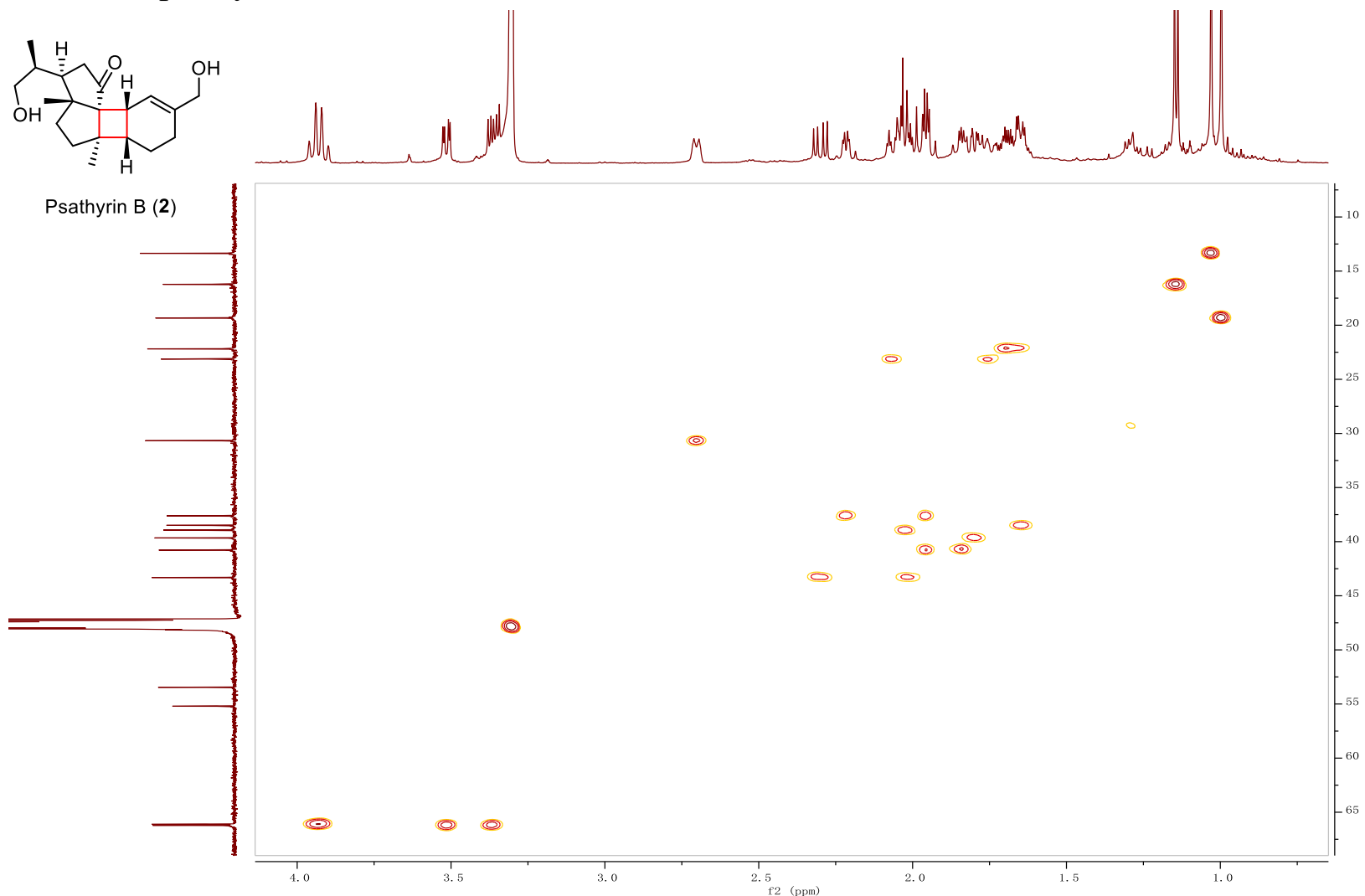

HMBC for psathyrin B (2)
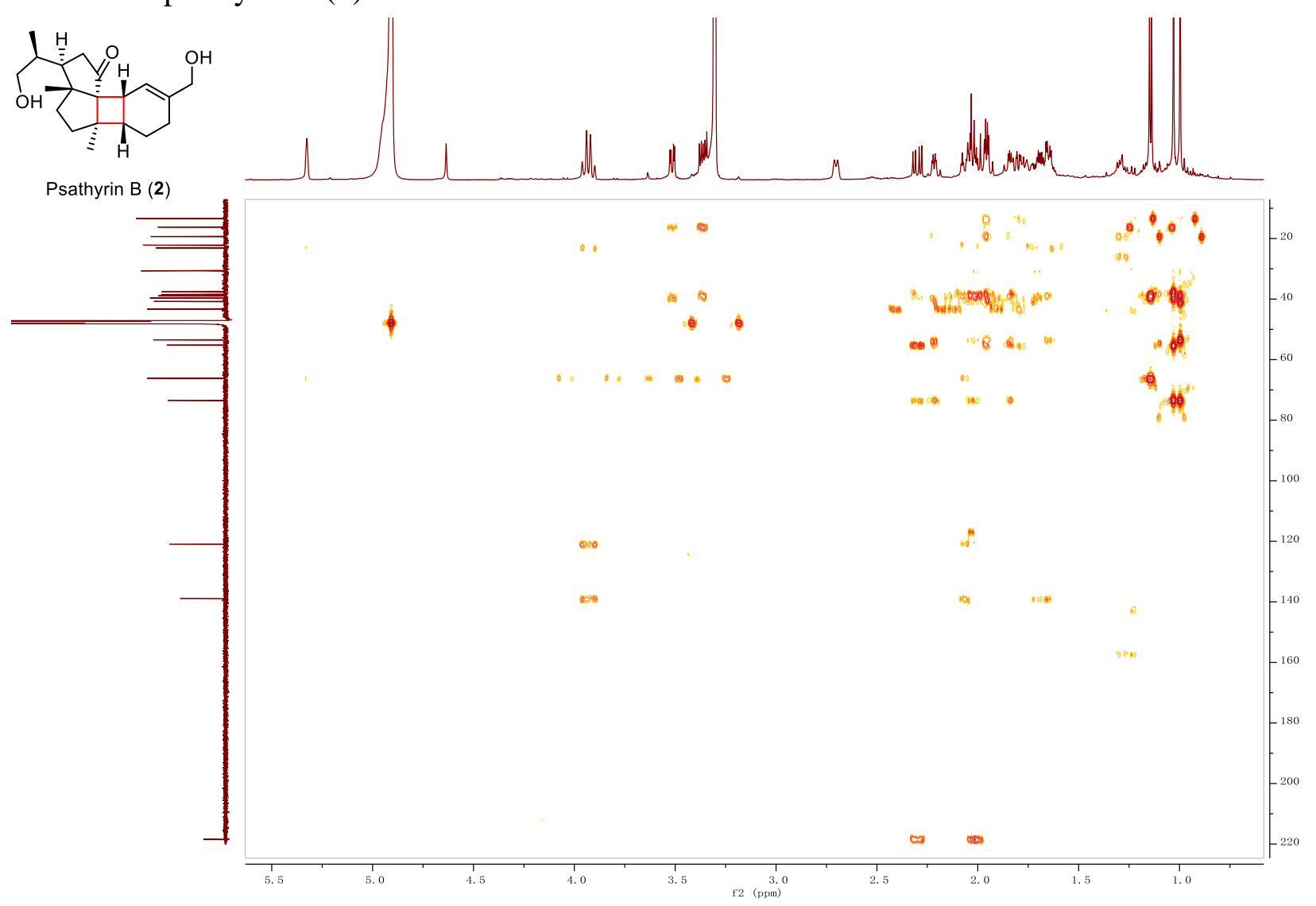
${ }^{1} \mathrm{H}-{ }^{1} \mathrm{H}$ COSY for psathyrin B (2)

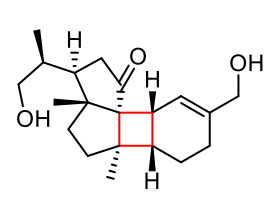

Psathyrin B (2)

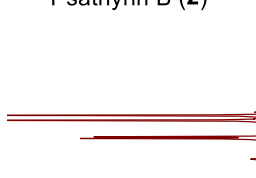

,

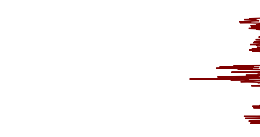

$$
\text { . }
$$

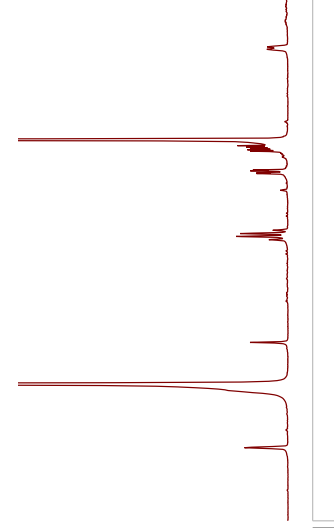

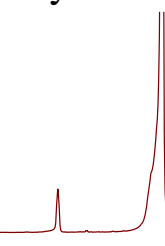

0

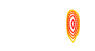

0

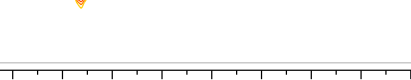

H. ut

0.0

(

60

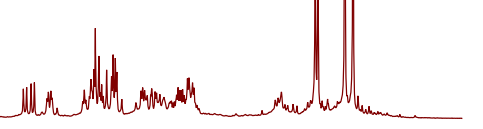

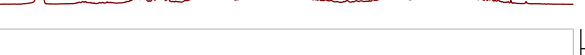

ROESY for psathyrin B (2)

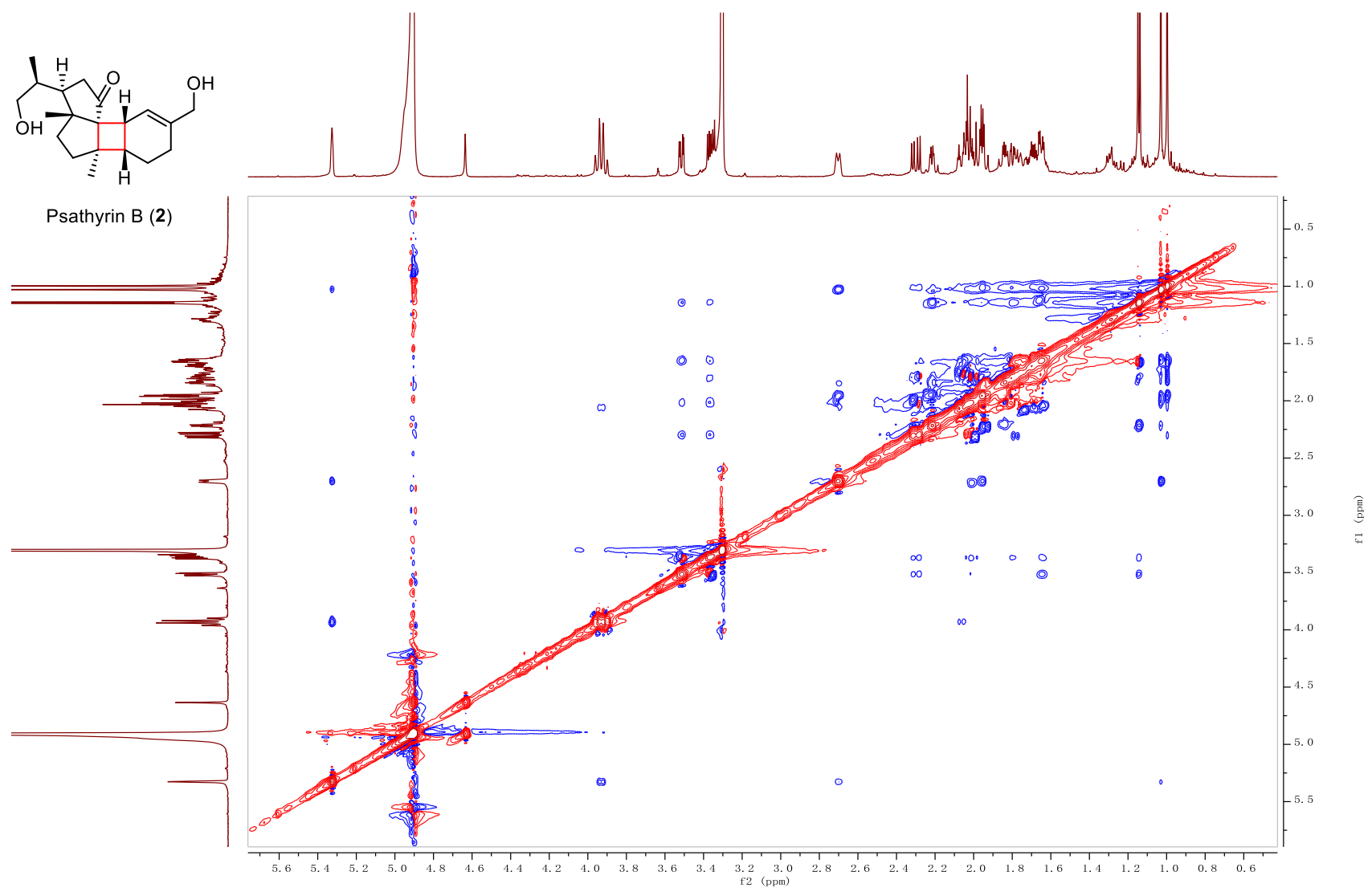


HR-ESIMS for psathyrin B (2)

LLB-69_190723164641\#13 RT: 0.17 AV: 1 NL: 5.41E6

T: FTMS + p ESI Full lock ms [150.0000-1100.0000]

341.20871

$\mathrm{C}_{20} \mathrm{H}_{30} \mathrm{O}_{3} \mathrm{Na}$

100

$-0.01841 \mathrm{ppm}$

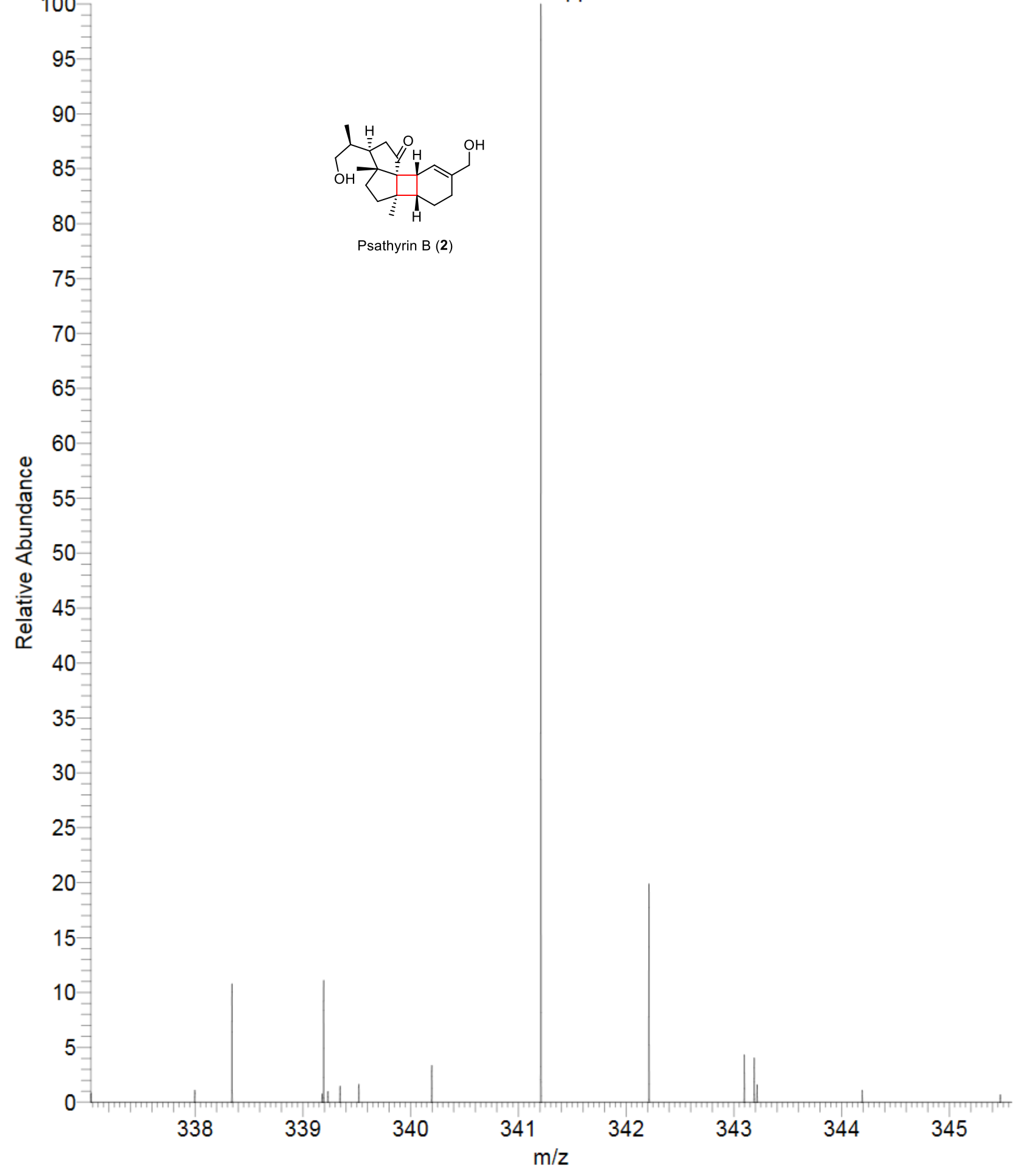

